\title{
Effect of Anemia on Health Related Quality of Life in Pediatric Inflammatory Bowel Disease: Comparison of a Single Center Cohort to Published Data
}

Istvan Danko* and Marcy Weidkamp

Department of Pediatrics, Division of Gastroenterology Hepatology and Nutrition, University of Wisconsin, Madison, WI 53792-4108, USA

\section{Abstract}

Publication History:

Background: Health related quality of life (HRQL) is a key outcome measure, increasingly used to Received: July 28, 2018

evaluate the efficacy of medical interventions. While anemia is the most common systemic complication Accepted: August 28, 2018 of inflammatory bowel disease (IBD) in children, the literature is scarce on its effect on HRQL.

Published: August 31, 2018

Aim: Evaluation of the association between anemia and HRQL in children with IBD.

Methods: PedsQL 4.0, a generic HRQL survey that assesses subjective perception of psychosocial and physical well-being from patient and parental perspective was administered to 30 children with IBD. Results were analyzed in patients with and without anemia, and with active and quiescent disease. Findings were compared to published data in pediatric IBD and healthy controls. Anemia was defined by WHO criteria. Active disease was defined by pediatric Crohn's disease or ulcerative colitis indices $>10$ and/or low albumin or elevated CRP.

\section{Keywords:}

Anemia, Children, Crohn's Disease, Health Related Quality of Life, Inflammatory Bowel Disease, Ulcerative colitis

Results: Within our cohort as a whole and among our patients in remission, anemia was associated with lower mean scores in multiple domains of the PedsQL 4.0 survey. Similarly, in these groups a higher proportion of patients had abnormal scores. Compared to published pediatric IBD data, our patients in remission with normal hemoglobin scored significantly higher in all HRQL domains, while there was no significant difference between the two cohorts as a whole. Compared to healthy controls our cohort as a whole and patients with anemia scored significantly lower in all parent-reported domains. In contrast, scores in patients with normal hemoglobin were not significantly different from healthy controls.

Conclusions: Anemia was associated with impaired HRQL in children with IBD including those in apparent remission.

\section{Introduction}

Health related quality of life (HRQL) is recognized as one of the most important outcome measures in the assessment of the efficacy new treatment modalities in pediatric inflammatory bowel disease (IBD) [1]. The effects of gastrointestinal symptoms on HRQL are well studied [2,3] but despite of the high prevalence of anemia in children with IBD [4], its impact on HRQL is not well understood.

Our aim was to investigate whether there is an association between anemia and impaired HRQL in children with IBD. We have administered PedsQL 4.0 [5], a generic HRQL survey, to a cohort of children with IBD treated with infliximab. PedsQL 4.0 is validated in pediatric IBD and allows comparison with healthy controls [6]. We analyzed mean HRQL scores, and the prevalence of subjects with low scores, predicting poor HRQL, among patients with anemia and normal hemoglobin, in both active and quiescent disease. In addition we compared HRQL scores in our cohort with published data in pediatric IBD [3], as well as healthy controls [5].

\section{Methods}

\section{Study overview}

The study was conducted at the American Family Children's Hospital, University of Wisconsin, School of Medicine and Public Health between February of 2014 and August of 2016. Inclusion criteria were: age 18 years or less, diagnosis of Crohn's Disease (CD) or ulcerative colitis (UC) and treatment with infliximab. Data collection for disease activity indices, HRQL and laboratory studies were done on the same day. For comparisons with published literature in pediatric IBD and healthy controls, data were extracted from the report by Kunz et al. on PedsQL 4.0 scores in a large pediatric multicenter IBD cohort [3] and from the original validation study for the PedsQL 4.0 survey [5] respectively.

\section{Laboratory studies}

Hematology indices, albumin and C-reactive protein (CRP), were measured by routine methods in the hospital clinical laboratory. Anemia was defined according to general WHO criteria as Hemoglobin $(\mathrm{Hb})<11.5 \mathrm{~g} / \mathrm{dl}$ in patients less than 11 years of age, $<12$ $\mathrm{g} / \mathrm{dl}$ in females, and $<13 \mathrm{~g} / \mathrm{dl}$ in males above 11 years of age. Cut-off from normal albumin was $3.3 \mathrm{~g} / \mathrm{dl}$ up to 8 years of age and $3.2 \mathrm{~g} / \mathrm{dl}$ above 8 years of age. CRP up to $1 \mathrm{mg} / \mathrm{dl}$ was considered normal.

\section{Assessment of disease activity and health-related quality of life}

Disease activity was assessed with pediatric CD or UC activity indices, PCDAI [7] and PUCAI [8], respectively. Patients were considered in remission if they had PCDAI or PUCAI scores of 10 or less, plus normal serum albumin and CRP.

"Corresponding Author: Dr. Istvan Danko, Department of Pediatrics, Division of Gastroenterology Hepatology and Nutrition, University of Wisconsin School of Medicine and Public Health, 600 Highland Avenue, Madison, WI 53792-4108, USA, Tel: (608) 262-0943, Fax: (608) 263-6210; E-mail: idanko@pediatrics.wisc.edu

Citation: Danko I, Weidkamp M (2018) Effect of Anemia on Health Related Quality of Life in Pediatric Inflammatory Bowel Disease: Comparison of a Single Center Cohort to Published Data. Int J Pediatr Neonat Care 4: 142. doi: https:// doi.org/10.15344/2455-2364/2018/142

Copyright: () 2018 Danko et al. This is an open-access article distributed under the terms of the Creative Commons Attribution License, which permits unrestricted use, distribution, and reproduction in any medium, provided the original author and source are credited. 
HRQL reflects a patient's perception of the impact of a chronic illness on core dimensions of physical and social functioning and can be assessed with disease-specific or generic surveys [9]. The PedsQL 4.0 (Pediatric Quality of Life Inventory) Generic Core Scales $[5,6]$ used in this study is a generic survey that assesses areas of physical and psychosocial functioning relevant for both healthy and ill populations [9], and normative data allow comparisons between patients with various diseases, or a particular disease and the general population. PedsQL 4.0 has been validated in pediatric IBD [1] PedsQL 4.0 scores range from 0 to 100 , higher scores indicate better HRQL. Results are reported as six consecutive numbers that represent child-reported psychosocial, physical and total (composite) scales followed by parent-reported values in the same order. Scores below $66.03,72.98$ and 69.71 for child self-report and $64.38,63.28$ and 65.42 for parent proxy-report are consistent with at risk status for poor HRQL [6] (henceforth referred to as "risk scores"). We have analyzed mean scores and the proportion of patients with risk scores as a function of anemia and/or active disease by dividing our study cohort into four subgroups: patients in remission with normal $\mathrm{Hb}$, patients in remission with anemia, patients with active disease and normal $\mathrm{Hb}$, and patients with active disease and anemia. HRQL scores in our cohort were then compared to scores published in pediatric IBD [3] and healthy controls [5]. In the final statistical analysis patients with active disease were treated as a single group regardless of the presence of anemia due to the very small number of patients with the unusual constellation of active disease and normal $\mathrm{Hb}$.

\section{Statistical analysis}

Patient and parent reported HRQL scores were summarized in terms of means and standard deviations and compared between groups using a two-sample t-test. The Levene test was utilized to examine whether the variances in the HRQL scores differ between groups. Comparisons of the proportions of subjects with anemia, active disease and risk scores were conducted using Fisher's exact test. All $p$ values are two-sided and $p<0.05$ was used for defining statistical significance. Statistical analyses were conducted using SAS software (SAS Institute Inc., Cary NC) version 9.4.

\section{Results}

\section{Clinical characteristics}

Table 1 shows summary of demographic and clinical data. All patients received infliximab for maintenance treatment. In addition, five patients took Prednisone at the time of the study. 17 patients representing almost half of those in remission and the majority of those with active disease had anemia. 12 patients representing the minority of those with normal $\mathrm{Hb}$ and more than half of those with anemia had active disease.

Detailed data of individual patients in our cohort are shown in Table 2. The groups with anemia (panels $B+D$ ) included all 3 patients with $\mathrm{UC}$ and 14 patients with $\mathrm{CD}$. All 13 patients with normal $\mathrm{Hb}$ (panels $A+C$ ) had CD. All patients, regardless of the presence of anemia, were iron deficient (not shown). Folate and B12 levels within one year of enrollment were available for all except 2 patients and were all normal; none of the patients had mean corpuscular volume above $90 \mathrm{fl}$ at the time of the study (not shown). All patients with active disease (panels $\mathrm{C}+\mathrm{D}$ ) had $\mathrm{CD}$. Of the 18 patients in remission (panels $\mathrm{A}+\mathrm{B}$ ), 3 had $\mathrm{UC}$ and 15 had CD.
Statistical comparisons between mean laboratory values, disease activity indices and HRQL scores in various subgroups of our cohort along with published data in pediatric IBD and healthy controls are shown in tables 3, 4 and 5. Summary of the underlying data is shown in Supplemental Table 1. Henceforth the reader is referred to this table for mean values of various parameters that are discussed in the study.

Mean $\mathrm{Hb}$ was lower in patients with active disease compared to those in remission but the difference was not statistically significant (not shown). Patients in remission both with anemia and normal $\mathrm{Hb}$ had normal mean albumin, CRP and low mean PCDA/PUCAI scores; there was no statistically significant difference between the two subgroups in these variables (not shown).

\section{Health-related quality of life in patients with anemia and active disease}

Table 2 shows distribution of PedsQL 4.0 risk scores among individual patients as a function of anemia and/or active disease. There is obvious clustering of risk scores in the subgroups with anemia and/or active disease (panels B, C, D; risk scores are shown in bold).

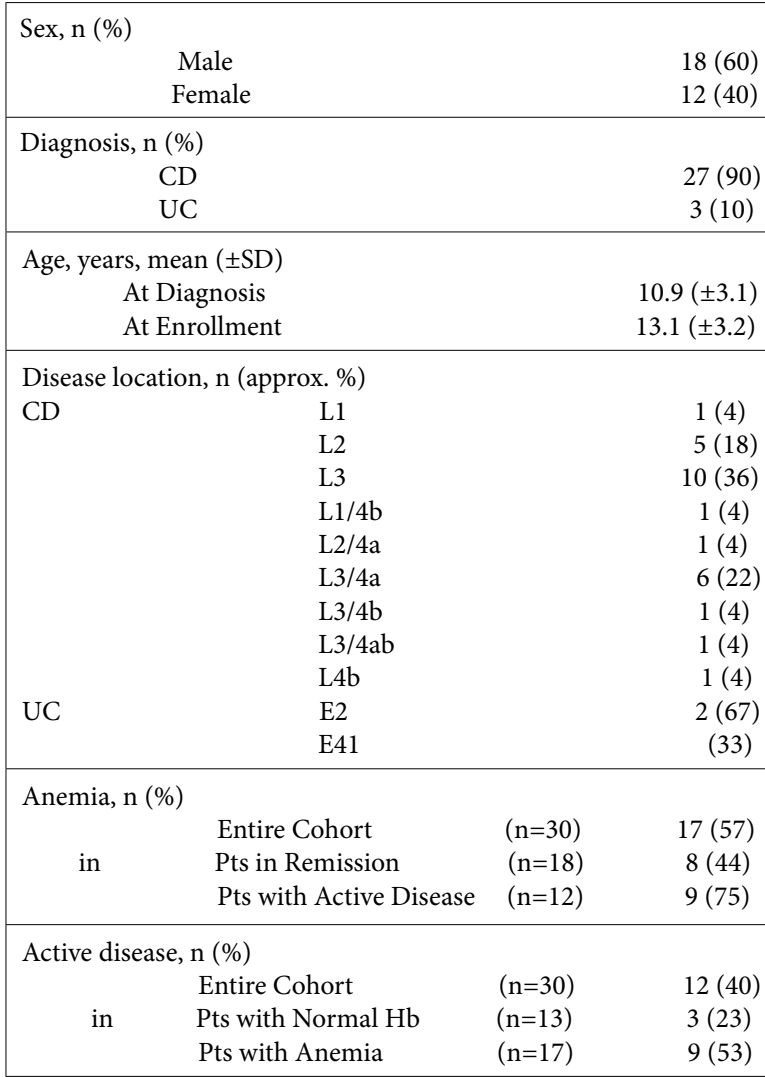

Table 1: Summary of Demographic and Clinical Data.

CD: Crohn's Disease, UC: Ulcerative Colitis, Hb: Hemoglobin, L, E: Paris class-ification categories for disease location in CD and UC, respectively, as follows: L1: ileal, L2: colonic, L3: ileocolonic, L1/4b: ileal with distal upper disease, L2/4a: colonic with proximal upper disease, L3/4a: ileocolonic with proximal upper disease, L3/4b: ileocolonic with distal upper disease, $\mathrm{L} 3 / 4 \mathrm{ab}$ : ileocolonic with both proximal and distal upper disease, L4b: distal upper disease only, E2: UC with left sided colitis, E4: UC with pancolitis, Pts: Patients. 
Citation: Danko I, Weidkamp M (2018) Effect of Anemia on Health Related Quality of Life in Pediatric Inflammatory Bowel Disease: Comparison of a Single Center Cohort to Published Data. Int J Pediatr Neonat Care 4: 142. doi: https://doi.org/10.15344/2455-2364/2018/142

Page 3 of 6

Patients with anemia had lower mean HRQL scores in all scales compared to patients with normal $\mathrm{Hb}$; the difference was statistically significant in parent-reported physical and total scales (Table 3, Aa). The proportion of children with risk scores was higher in all scales among patients with anemia compared to those with normal $\mathrm{Hb}$ (Table 4, Aa vs Ab), but the difference was not statistically significant (Table 3, Ba).
Patients with active disease had lower mean scores in all scales compared to patients in remission but the differences were not statistically significant (Table 3, Ab). Similarly, the proportion of patients with risk scores was higher in all scales except the patientreported psychosocial scale among patients with active disease compared to those in remission (Table $4, \mathrm{~B}$ vs $\mathrm{C}$ ), however, the differences were not statistically significant (Table $3, \mathrm{Bb}$ ).

\begin{tabular}{|c|c|c|c|c|c|c|c|c|c|c|c|c|c|c|c|c|}
\hline \multirow{3}{*}{$\mathrm{Pt} \#$} & \multirow{2}{*}{\multicolumn{3}{|c|}{ Demographics }} & \multirow{3}{*}{$\mathrm{Dx}$} & \multirow{3}{*}{$\begin{array}{l}\text { Paris } \\
\text { Classif. }\end{array}$} & \multirow{3}{*}{$\begin{array}{l}\text { Anemia } \\
\mathrm{Hb} \\
(\mathrm{g} / \mathrm{dl})\end{array}$} & \multirow{2}{*}{\multicolumn{4}{|c|}{ Disease Activity }} & \multicolumn{6}{|c|}{ PedsQL 4.0 Scores } \\
\hline & & & & & & & & & & & \multicolumn{3}{|c|}{ Patient-reported } & \multicolumn{3}{|c|}{ Parent-reported } \\
\hline & $\begin{array}{l}\text { Age at } \\
\text { Dx }\end{array}$ & $\begin{array}{l}\text { Age at } \\
\text { Enrollment }\end{array}$ & $\begin{array}{l}\mathrm{M} \\
\text { or F }\end{array}$ & & & & $\begin{array}{c}\text { CRP } \\
(\mathrm{mg} / \mathrm{dL})\end{array}$ & $\begin{array}{c}\text { Alb } \\
(\mathrm{g} / \mathrm{dL})\end{array}$ & $\begin{array}{c}\text { PCD } \\
\text { AI }\end{array}$ & $\begin{array}{c}\text { PUC } \\
\text { AI }\end{array}$ & Ps & Phys & Total & Ps & Phys & Total \\
\hline A & \multicolumn{16}{|c|}{ Patients in Remission with Normal Hemoglobin $(\mathrm{n}=10)$} \\
\hline 1 & 7 & 14 & M & $\mathrm{CD}$ & L1 & 13.1 & 0.2 & 3.3 & 7 & & 71 & $72^{1}$ & 71 & 81 & 97 & 87 \\
\hline 2 & 13 & 16 & F & $\mathrm{CD}$ & L3 & 12.4 & 0.0 & 3.6 & 5 & & 95 & 100 & 97 & 100 & 94 & 98 \\
\hline 3 & 16 & 17 & F & $\mathrm{CD}$ & $\mathrm{L} 3 / 4 \mathrm{a}$ & 13.4 & 0.5 & 3.7 & 5.0 & & 68 & 88 & 75 & 75 & 84 & 78 \\
\hline 4 & 14 & 15 & F & $\mathrm{CD}$ & L3 & 12.6 & 0.0 & 3.7 & 0.0 & & 100 & 91 & 97 & 92 & 78 & 87 \\
\hline 5 & 11 & 14 & $\mathrm{M}$ & $\mathrm{CD}$ & L3 & 13.9 & 0.0 & 4.2 & 0.0 & & 97 & 94 & 96 & 93 & 94 & 93 \\
\hline 6 & 14 & 15 & $\mathrm{M}$ & $\mathrm{CD}$ & L2 & 14.6 & 0.0 & 3.5 & 5.0 & & 90 & 94 & 91 & 85 & 94 & 88 \\
\hline 7 & 13 & 15 & $\mathrm{~F}$ & $\mathrm{CD}$ & $\mathrm{L} 3 / 4 \mathrm{a}$ & 12.7 & 1.0 & 3.6 & 5.0 & & 93 & 91 & 92 & 85 & 88 & 86 \\
\hline 8 & 13 & 15 & $\mathrm{M}$ & $\mathrm{CD}$ & $\mathrm{L} 3 / 4 \mathrm{~b}$ & 13.3 & 0.0 & 3.6 & 1.3 & & 82 & 97 & 87 & 83 & 100 & 89 \\
\hline 9 & 13 & 15 & $\mathrm{M}$ & $\mathrm{CD}$ & L3 & 13.3 & 0.0 & 4.2 & 0.0 & & 67 & 100 & 78 & 75 & 91 & 80 \\
\hline 10 & 13 & 16 & $\mathrm{M}$ & $\mathrm{CD}$ & $\mathrm{L} 3 / 4 \mathrm{a}$ & 13.4 & 0.0 & 4.0 & 0.0 & & 88 & 97 & 91 & 87 & 100 & 91 \\
\hline B & \multicolumn{16}{|c|}{ Patients in Remission with Anemia $(\mathrm{n}=8)$} \\
\hline 1 & 9 & 15 & M & $\mathrm{CD}$ & $\mathrm{L} 2$ & 12.9 & 0.0 & 4.0 & 10 & & 77 & 84 & 79 & $58^{1}$ & 81 & $61^{1}$ \\
\hline 2 & 11 & 13 & $\mathrm{~F}$ & UC & E2 & 11.9 & 0.0 & 3.2 & & 5 & $60^{1}$ & $72^{1}$ & $64^{1}$ & $33^{1}$ & $44^{1}$ & $37^{1}$ \\
\hline 3 & 13 & 17 & F & $\mathrm{CD}$ & L3 & 10.0 & 0.0 & 3.2 & 7.5 & & $38^{1}$ & $63^{1}$ & $47^{1}$ & 80 & 94 & 85 \\
\hline 4 & 14 & 16 & M & UC & E4 & 8.9 & 0.0 & 3.4 & & 0 & 85 & 84 & 85 & 80 & 84 & 82 \\
\hline 5 & 8 & 9 & $\mathrm{M}$ & UC & E2 & 8.1 & 0.0 & 4.0 & & 0 & 97 & 100 & 98 & 87 & 94 & 89 \\
\hline 6 & 13 & 13 & $\mathrm{M}$ & $\mathrm{CD}$ & L3 & 12.0 & 0.0 & 3.7 & 10.0 & & $58^{1}$ & $59^{1}$ & $59^{1}$ & $63^{1}$ & 69 & $65^{1}$ \\
\hline 7 & 17 & 17 & $\mathrm{~F}$ & $\mathrm{CD}$ & L3 & 11.8 & 0.0 & 3.2 & 5.0 & & 67 & $38^{1}$ & $57^{1}$ & $50^{1}$ & $50^{1}$ & $50^{1}$ \\
\hline 8 & 9 & 14 & $\mathrm{M}$ & $\mathrm{CD}$ & L3 & 12.8 & 1.0 & 3.5 & 0.0 & & 88 & 84 & 87 & $63^{1}$ & $59^{1}$ & $62^{1}$ \\
\hline $\mathrm{C}$ & \multicolumn{16}{|c|}{ Patients with Active Disease and Normal Hemoglobin $(\mathrm{n}=3)$} \\
\hline 1 & 6 & 7 & $\mathrm{~F}$ & $\mathrm{CD}$ & $\mathrm{L} 3 / 4 \mathrm{a}$ & 11.7 & 1.0 & 2.5 & 35 & & 67 & $69^{1}$ & $67^{1}$ & $60^{1}$ & $63^{1}$ & $61^{1}$ \\
\hline 2 & 5 & 7 & M & $\mathrm{CD}$ & $\mathrm{L} 2$ & 11.5 & 1.0 & 3.4 & 32.5 & & $63^{1}$ & $50^{1}$ & $59^{1}$ & $45^{1}$ & 66 & $52^{1}$ \\
\hline 3 & 12 & 14 & M & $\mathrm{CD}$ & $\mathrm{L} 3$ & 13.6 & 1.2 & 4.3 & 0.0 & & 72 & 78 & 74 & 77 & 91 & 82 \\
\hline $\mathrm{D}$ & \multicolumn{16}{|c|}{ Patients with Active Disease and Anemia $(n=9)$} \\
\hline 1 & 9 & 14 & M & $\mathrm{CD}$ & $\mathrm{L} 2$ & 10.5 & 0.0 & 3.6 & 18 & & 73 & $69^{1}$ & 72 & $63^{1}$ & $63^{1}$ & $63^{1}$ \\
\hline 2 & 12 & 12 & $\mathrm{~F}$ & $\mathrm{CD}$ & $\mathrm{L} 1 / 4 \mathrm{~b}$ & 11.9 & 2.0 & 2.7 & 10.0 & & 92 & 84 & 89 & 78 & 84 & 80 \\
\hline 3 & 7 & 8 & $\mathrm{~F}$ & $\mathrm{CD}$ & $\mathrm{L} 3 / 4 \mathrm{a}$ & 10.8 & 0.0 & 3.2 & 40.0 & & 85 & $72^{1}$ & 80 & 85 & 69 & 79 \\
\hline 4 & 9 & 11 & $\mathrm{M}$ & $\mathrm{CD}$ & $\mathrm{L} 2 / 4 \mathrm{a}$ & 12.1 & 3.0 & 2.6 & 27.5 & & 90 & $66^{1}$ & 82 & 87 & $59^{1}$ & 77 \\
\hline 5 & 5 & 6 & $\mathrm{M}$ & $\mathrm{CD}$ & $\mathrm{L} 3 / 4 \mathrm{ab}$ & 9.7 & 1.0 & 2.7 & 32.5 & & 67 & $69^{1}$ & $67^{1}$ & 77 & 66 & 73 \\
\hline 6 & 10 & 12 & $\mathrm{~F}$ & $\mathrm{CD}$ & $\mathrm{L} 4 \mathrm{~b}$ & 11.3 & 1.0 & 2.4 & 40.0 & & 87 & 81 & 85 & $62^{1}$ & $53^{1}$ & $59^{1}$ \\
\hline 7 & 11 & 11 & $\mathrm{M}$ & $\mathrm{CD}$ & $\mathrm{L} 3$ & 10.9 & 0.0 & 3.5 & 12.5 & & $58^{1}$ & $66^{1}$ & $61^{1}$ & $50^{1}$ & $63^{1}$ & $54^{1}$ \\
\hline 8 & 9 & 16 & M & $\mathrm{CD}$ & $\mathrm{L} 3 / 4 \mathrm{a}$ & 12.9 & 1.0 & 3.2 & 12.5 & & 82 & 100 & 88 & 82 & 97 & 87 \\
\hline 9 & 10 & 10 & $\mathrm{~F}$ & $\mathrm{CD}$ & $\mathrm{L} 2$ & 9.3 & 1.0 & 3.7 & 12.5 & & 98 & 100 & 99 & 87 & 88 & 87 \\
\hline
\end{tabular}

Table 2: Detailed Demographics, Clinical Data and Distribution of Risk Scores.

': risk scores; Pt: patient; Dx: diagnosis; M: male, F: female; Hb: Hemoglobin; CRP: C-reactive protein; Alb: albumin; PCDAI: pediatric Crohn's disease activity index; PUCAI: Pediatric ulcerative colitis activity index; Ps: psychosocial; Phys: physical; M: male; F: female; CD: Crohn's disease; UC: Ulcerative Colitis; L, E: Paris classification categories for disease location in CD and UC, respectively, see Table 1. 
Patients in remission who had anemia had lower mean scores in all scales compared to patients in remission with normal $\mathrm{Hb}$. Differences were statistically significant in all except the patient-reported psychosocial scale (Table 3, Ac). Similarly, in the group with quiescent disease the proportion of patients with risk scores was higher in all scales among those who had anemia (Table 4, Ca vs $\mathrm{Cb}$ ). These differences were statistically significant in patient-reported total scales and parent-reported psychosocial and total scales (Table 3, Bc).

\section{Comparisons to published data in children with IBD}

Compared to the published multicenter pediatric IBD cohort [3], mean HRQL scores of our entire cohort were somewhat lower in all except the patient-reported psychosocial scale, but these differences were not statistically significant (Table $5, \mathrm{Aa}$ ). At the same time, mean scores were significantly lower in our patients with anemia in all parent reported scales (Table 5, Aai), in our patients with active disease in parent-reported physical scales (Table $5, \mathrm{Ab}$ ), and in our anemic patients in remission in parent-reported psychosocial and total scales (Table 5, Aci). In contrast, our patients in remission with normal $\mathrm{Hb}$ had significantly higher mean scores in all patient and parent reported scales (Table 5, Acii). This was remarkable considering the overall lower scores in our entire cohort.

Compared to published patients with active disease mean scores in physical scales were lower in our patients with active disease but the difference was not statistically significant (not shown). Compared to published patients in remission mean scores in physical scales were slightly lower in our patients in remission but the difference was not statistically significant (not shown). No published scores in other scales were available for comparisons.

\section{Comparisons to healthy controls}

In patient-reported physical scales our patients with normal $\mathrm{Hb}$ scored slightly higher, and patients in remission with normal $\mathrm{Hb}$ scored significantly higher (Table 5, Bcii) compared to healthy controls. In the other subgroups and remaining scales, mean patientreported scores were lower but not significantly different (Table 5, B, patient-reported columns).

At the same time, mean scores were significantly lower in all parentreported scales in our entire study cohort (Table 5, Ba), in our patients with anemia (Table 5, Bai), in our patients with active disease (Table 5, $\mathrm{Bb}$ ) and in our patients in remission who had anemia (Table 5, B ci) In the entire group of our patients in remission, mean parent-reported scores were also significantly lower in all except the physical scales (Table 5, Bc). In contrast, there was no significant decrease in mean parent-reported scores compared to healthy controls in patients with normal $\mathrm{Hb}$ in the entire cohort, and among those with normal $\mathrm{Hb}$ in remission (Table5, Baii and Bcii, respectively).

\section{Discussion}

To our knowledge, this is the first study to analyze HRQL in children with IBD as a function of anemia with comparisons to published data in pediatric IBD cohorts and healthy controls. This is also the first study that examines HRQL scores in the context of validated cutoff levels below which subjects are at risk for poor HRQL. Relating HRQL scores to such cut-off values provides clues to their true clinical significance.
We have found that a sizable proportion of patients had scores consistent with poor HRQL in all areas of the PedsQL 4.0 survey except those who were both in remission and had no anemia. The association of anemia with impaired HRQL was also supported by the comparisons of our patients to unselected IBD cohorts and healthy controls. Our study demonstrated divergence of patient and parental assessments, underscoring the importance of obtaining both perspectives when evaluating HRQL in these children.

HRQL scores in our patients in remission were higher compared to those with active disease. Although the differences did not reach statistical significance these findings are consistent with published data on the negative impact of disease activity on HRQL in IBD $[10,11]$.

Our most intriguing finding was the association of anemia with lower HRQL scores in patients with apparently quiescent disease. This association was less prominent in our cohort as a whole, likely due to the confounding effect of disease activity. A limitation of our study is that we do not have endoscopic or fecal calprotectin data to further confirm disease remission. In some children anemia may have been an indicator of occult disease activity missed by traditional clinical assessments and conventional laboratory markers, similar to elevated fecal calprotectin reported in clinically inactive patients [12]. In either case, anemia in children in apparent remission appears to be an important red flag that should alert physicians to the need for optimization of treatment for anemia, inflammation, or both.

\section{Authors' Contributions}

Istvan Danko:

Conception and design of the work, acquisition, analysis, interpretation of data for the work.

Drafting the work and revising it critically for important intellectual content.

Final approval of the version to be published.

Agreement to be accountable for all aspects of the work in ensuring that questions related to the accuracy or integrity of any part of the work are appropriately investigated and resolved.

\section{Marcy Weidkamp:}

Acquisition of data.

Critical review of the work.

Final approval of the version to be published.

Agreement to be accountable for all aspects of the work in ensuring that questions related to the accuracy or integrity of any part of the work are appropriately investigated and resolved.

\section{Acknowledgments}

The authors greatly appreciate the help with statistical analysis by Jens C. Eickhoff, PhD, Department of Biostatistics \& Medical Informatics, University of Wisconsin, Madison.

\section{Funding}

The research was supported from research and development funds of the Department of Pediatrics, University of Wisconsin, School of Medicine and Public Health. 
Citation: Danko I, Weidkamp M (2018) Effect of Anemia on Health Related Quality of Life in Pediatric Inflammatory Bowel Disease: Comparison of a Single Center Cohort to Published Data. Int J Pediatr Neonat Care 4: 142. doi: https://doi.org/10.15344/2455-2364/2018/142

Page 5 of 6

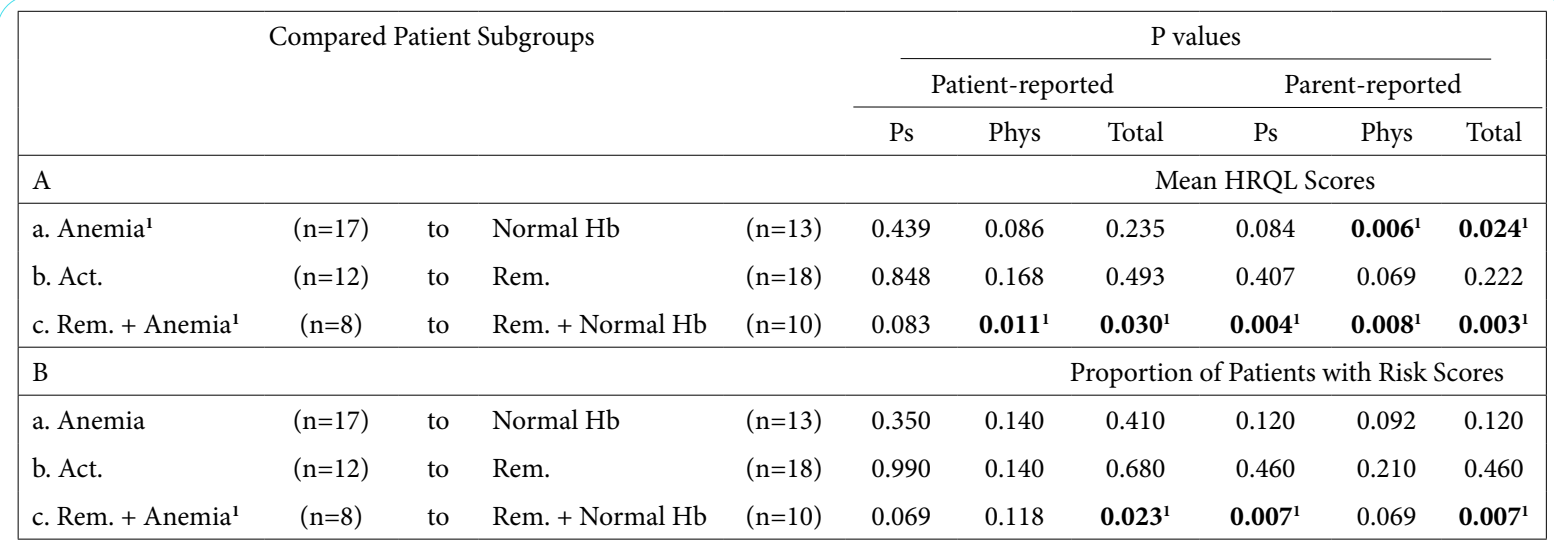

Table 3: Statistical Comparison of HRQL Scores and Proportion of Patients with Risk Scores between Subgroups.

A: P values from two-sample t tests; B: P values from Fisher's exact test; Act.: Active Disease; Rem.: Remission; ${ }^{1}$ Groups with more abnormal values (lower HRQL scores, higher proportion of patients with risk scores) reaching statistical significance and corresponding P values; Ps: psychosocial; Phys: physical.

\begin{tabular}{|c|c|c|c|c|c|c|c|c|}
\hline \multirow[t]{2}{*}{ Patient Groups } & & & \multicolumn{3}{|c|}{ Patient-reported } & \multicolumn{3}{|c|}{ Parent-reported } \\
\hline & & & Ps & Phys & Total & Ps & Phys & Total \\
\hline \multirow[t]{3}{*}{ A Entire Study Cohort } & & $(\mathrm{n}=30)$ & $17 \%$ & $40 \%$ & $27 \%$ & $33 \%$ & $27 \%$ & $33 \%$ \\
\hline & a. Anemic & $(n=17)$ & $24 \%$ & $53 \%$ & $35 \%$ & $47 \%$ & $41 \%$ & $47 \%$ \\
\hline & b. Normal Hb & $(n=13)$ & $8 \%$ & $23 \%$ & $15 \%$ & $15 \%$ & $8 \%$ & $15 \%$ \\
\hline \multirow{2}{*}{ C Remission } & a. Anemic & $(n=8)$ & $38 \%$ & $50 \%$ & $50 \%$ & $63 \%$ & $38 \%$ & $63 \%$ \\
\hline & b. Normal Hb & $(\mathrm{n}=10)$ & $0 \%$ & $10 \%$ & $0 \%$ & $0 \%$ & $0 \%$ & $0 \%$ \\
\hline
\end{tabular}

Table 4. Proportion of Patients with Risk Scores in various PedsQL 4.0 Scales.

Ps: psychosocial; Phys: physical

\begin{tabular}{|c|c|c|c|c|c|c|c|}
\hline \multirow[t]{3}{*}{ Patient Groups } & & \multicolumn{5}{|c|}{$\mathrm{P}$ values } & \\
\hline & & \multicolumn{3}{|c|}{ Patient-reported } & \multicolumn{3}{|c|}{ Parent-reported } \\
\hline & & Ps & Phys & Total & Ps & Phys & Total \\
\hline A & Compared to & \multicolumn{6}{|c|}{$\operatorname{IBD}(n=136)$} \\
\hline a. Entire Study Cohort & $(n=30)$ & 0.774 & 0.321 & 0.777 & 0.160 & 0.284 & 0.134 \\
\hline i. Anemic & $(\mathrm{n}=17)$ & 0.970 & 0.160 & 0.580 & $0.048^{1}$ & $0.026^{1}$ & $0.021^{1}$ \\
\hline ii. Normal Hb & $(n=13)$ & 0.260 & 0.350 & 0.280 & 0.730 & 0.130 & 0.480 \\
\hline b. Active Disease & $(n=12)$ & 0.720 & 0.150 & 0.660 & 0.120 & $0.037^{1}$ & 0.046 \\
\hline c. Remission & $(n=18)$ & 0.550 & 0.690 & 0.600 & 0.600 & 0.790 & 0.720 \\
\hline i. Anemic & $(n=8)$ & 0.455 & 0.195 & 0.303 & $0.031^{1}$ & 0.156 & $0.043^{1}$ \\
\hline ii. Normal Hb & $(n=10)$ & $0.036^{2}$ & $0.001^{2}$ & $0.006^{2}$ & $0.011^{2}$ & $<0.001^{2}$ & $<0.001^{2}$ \\
\hline B & Compared to & \multicolumn{6}{|c|}{ Healthy Controls $(n=399-717)^{3}$} \\
\hline a. Entire Study Cohort & $(n=30)$ & 0.081 & 0.070 & 0.054 & $<0.001^{1}$ & $<0.001^{1}$ & $<0.001^{1}$ \\
\hline i. Anemic & $(\mathrm{n}=17)$ & 0.17 & 0.051 & 0.094 & $<0.001^{1}$ & $<0.001^{1}$ & $<0.001^{1}$ \\
\hline ii. Normal Hb & $(n=13)$ & 0.720 & 0.670 & 0.940 & 0.120 & 0.640 & 0.170 \\
\hline b. Active Disease & $(n=12)$ & 0.250 & 0.054 & 0.120 & $0.004^{1}$ & $0.001^{1}$ & $<0.001^{1}$ \\
\hline c. Remission & $(\mathrm{n}=18)$ & 0.410 & 0.880 & 0.530 & $0.017^{1}$ & 0.140 & $0.027^{1}$ \\
\hline i. Anemic & $(n=8)$ & 0.105 & 0.098 & 0.082 & $<0.001^{1}$ & $0.012^{1}$ & $0.001^{1}$ \\
\hline ii. Normal Hb & $(\mathrm{n}=10)$ & 0.497 & $0.004^{2}$ & 0.144 & 0.691 & 0.244 & 0.992 \\
\hline
\end{tabular}

Table 5: Statistical Comparison of Mean HRQL Scores to Published Data.

P values from two-sample t tests; Ps: psychosocial; Phys: physical; ${ }^{1}:$ significantly lower scores in our cohort; ${ }^{2}$ : significantly higher scores in our cohort; ${ }^{3}$ : for detailed sample sizes see footnote to Supplemental Table 1. 
Citation: Danko I, Weidkamp M (2018) Effect of Anemia on Health Related Quality of Life in Pediatric Inflammatory Bowel Disease: Comparison of a Single Center Cohort to Published Data. Int J Pediatr Neonat Care 4: 142. doi: https://doi.org/10.15344/2455-2364/2018/142

Page 6 of 6

\section{Competing Interests}

The authors declare that no competing interests is present.

\section{References}

1. Mackner LM, Greenley RN, Szigethy E, Herzer M, Deer K, et al. (2013) Psychosocial issues in pediatric inflammatory bowel disease: report of the North American Society for Pediatric Gastroenterology, Hepatology, and Nutrition. J Pediatr Gastroenterol Nutr 56: 449-458.

2. Karwowski CA, Keljo D, Szigethy E (2009) Strategies to improve quality of life in adolescents with inflammatory bowel disease. Inflamm Bowel Dis 15: $1755-1764$.

3. Kunz JH, Hommel KA, Greenley RN (2010) Health-related Quality of Life of Youth with Inflammatory Bowel Disease: A Comparison with Published Data Using the PedsQL 4.0 Generic Core Scales. Inflamm Bowel Dis 16 939-946.

4. Goodhand JR, Kamperidis N, Rao A, Laskaratos F, McDermott A, et al (2012) Prevalence and management of anemia in children, adolescents, and adults with inflammatory bowel disease. Inflamm Bowel Dis 18: 513519.

5. Varni JW, Seid M, Kurtin PS (2001) PedsQL 4.0: reliability and validity of the Pediatric Quality of Life Inventory version 4.0 generic core scales in healthy and patient populations. Medical care 39: 800-812.

6. Varni JW, Burwinkle TM, Seid M, Skarr D (2003) The PedsQL 4.0 as a pediatric population health measure: feasibility, reliability, and validity. Ambul Pediatr 3: 329-341.

7. Hyams JS, Ferry GD, Mandel FS, Gryboski JD, Kibort PM, et al. (1991) Development and validation of a pediatric Crohn's disease activity index. $J$ Pediatr Gastroenterol Nutr 12: 439-447.

8. Turner D, Otley AR, Mack D, Hyams J, de Bruijne J, et al. (2007) Development, validation, and evaluation of a pediatric ulcerative colitis activity index: a prospective multicenter study. Gastroenterology 133: 423432

9. Palermo TM, Long AC, Lewandowski AS, Drotar D, Quittner AL, et al. (2008) Evidence-based assessment of health-related quality of life and functional impairment in pediatric psychology. J Pediatr Psychol 33: 983-996.

10. Cunningham C, Drotar D, Palermo TM, McGowan K, Arendt R, et al. (2007) Health-related quality of life in children and adolescents with inflammatory bowel disease. Child Health Care 36: 29-43.

11. Perrin JM, Kuhlthau K, Chughtai A, Romm D, Kirschner BS, et al. (2008) Measuring quality of life in pediatric patients with inflammatory bowel disease: psychometric and clinical characteristics. J Pediatr Gastroenterol Nutr 46: 164-171.

12. Samson CM, Morgan P, Williams E, Beck L, Addie-Carson R, et al. (2012) Improved outcomes with quality improvement interventions in pediatric inflammatory bowel disease. J Pediatr Gastroenterol Nutr 55: 679-688. 
Citation: Danko I, Weidkamp M (2018) Effect of Anemia on Health Related Quality of Life in Pediatric Inflammatory Bowel Disease: Comparison of a Single Center Cohort to Published Data. Int J Pediatr Neonat Care 4: 142. doi: https://doi.org/10.15344/2455-2364/2018/142

\section{Supplemental Table}

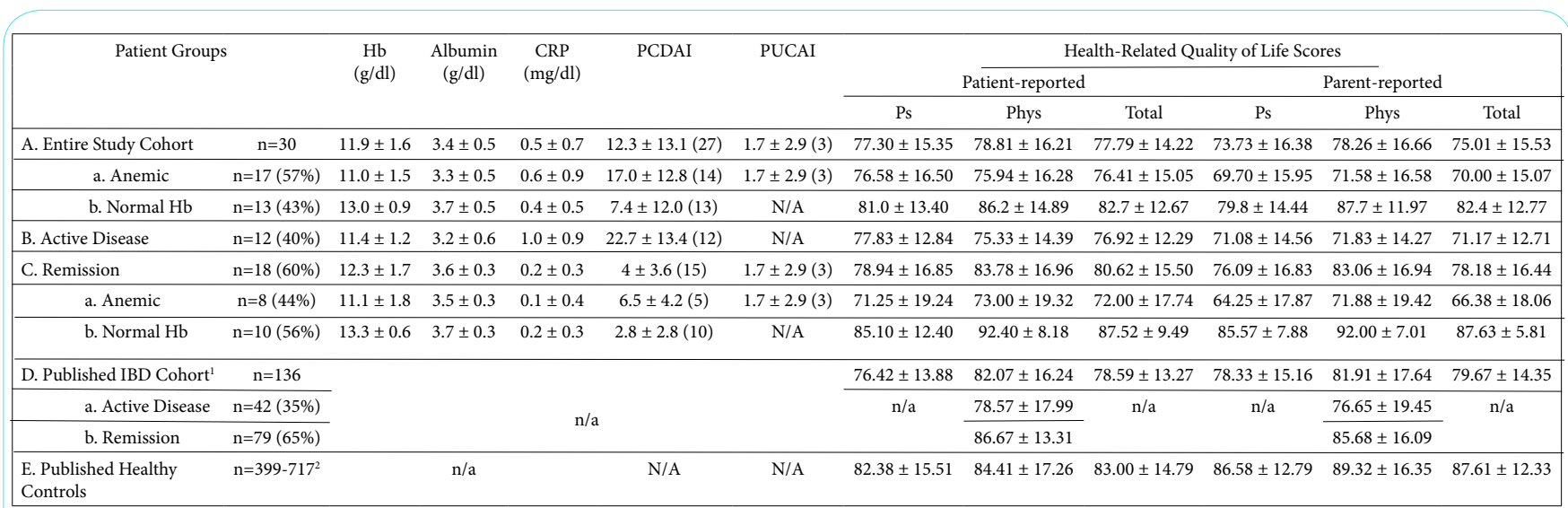

Supplemental Table 1. Serum Hemoglobin, Disease Activity Indicators and HRQL Scores.

Data shown as mean \pm SD (n); Hb: Hemoglobin, CRP: C-reactive protein, PCDAI: Pediatric Crohn’s Disease Activity Index, PUCAI: Pediatric Ulcerative Colitis Activity Index; Ps: psychosocial; Phys: physical N/A: not applicable, n/a: data not available; ${ }^{\prime}:$ In the published IBD sample the respective number (\%) of patients with Crohn's, ulcerative and indeterminate colitis was 100 (73.5), 34 (25) and 2 (1.5), (see Kunz et

al., Ref. \#3). ${ }^{2}$ : Sample sizes for healthy controls were: $399,400,401$ in respective patient reported scales, and 717 in all parent-reported scales (see Varni et al., Ref. \#5). 